\title{
miRNA164-directed cleavage of ZmNAC1 confers lateral root development in maize (Zea mays L.)
}

Jing $\mathrm{Li}^{1,2+}$, Guanghui Guo ${ }^{1,2+}$, Weiwei Guo ${ }^{1,2}$, Ganggang Guo ${ }^{1,2}$, Dan Tong ${ }^{1,2}$, Zhongfu Ni ${ }^{1,2}$, Qixin Sun ${ }^{1,2}$ and Yingyin $\mathrm{YaO}^{1,2,3^{*}}$

\begin{abstract}
Background: MicroRNAs are a class of small, non-coding RNAs that regulate gene expression by binding target mRNA, which leads to cleavage or translational inhibition. The NAC proteins, which include NAM, ATAF, and CUC, are a plant-specific transcription factor family with diverse roles in development and stress regulation. It has been reported that miR164 negatively regulates NAC1 expression, which in turn affects lateral root development in Arabidopsis; however, little is known about the involvement of the maize NAC family and miR164 in lateral root development.
\end{abstract}

Results: We collected 175 maize transcripts with NAC domains. Of these, 7 ZmNACs were putative targets for regulation by miR164. We isolated one gene, called TC258020 (designated ZmNAC1) from 2 maize inbred lines, 87-1 and Zong3. ZmNAC1 had a high expression level in roots and showed higher abundance (1.8 fold) in Zong3 relative to 87-1, which had less lateral roots than Zong3. There was a significant correlation between the expression level of $Z m N A C 1$ and the lateral root density in the recombinant inbred line (RIL) population. Transgenic Arabidopsis that overexpressed ZmNAC1 had increased lateral roots in comparison to the wild type. These findings suggest that $Z$ ImNAC1 played a significant role in lateral root development. An allelic expression assay showed that trans-regulatory elements were the dominant mediators of ZmNAC1 differential expression in 87-1 and Zong3, and further analysis revealed that miR164 was a trans-element that guided the cleavage of endogenous ZmNAC1 mRNA. Both mature miR164 and miR164 precursors had higher expression in 87-1 than Zong3, which was the opposite of the expression pattern of ZmNAC1. Additionally, the allelic assay showed that the cis-regulatory element most likely affected Zm-miR164b's expression pattern. A $\beta$-glucuronidase (GUS) assay showed that the Zm-miR164b promoter had higher GUS activity in 87-1 than in Zong3. In addition, we detected miR164b expression in the RIL population, and the results indicated that miR164b had a higher expression level in the RILs containing 87-1 promoter than those containing Zong3 promoter.

Conclusion: Our results indicate one possible pathway in maize by which differences in miR164b promoter activity resulted in a different expression pattern for mature miR164 which negatively regulates ZmNAC1 expression in 87-1 and Zong3, thereby contributing to a significantly different lateral root phenotype.

Keywords: Maize ZmNAC1, miR164, Lateral root

\footnotetext{
*Correspondence: yingyin@cau.edu.cn

${ }^{\dagger}$ Equal contributors

'State Key Laboratory for Agrobiotechnology and Key Laboratory of Crop Heterosis and Utilization (MOE) and Key Laboratory of Crop Genomics and Genetic Improvement (MOA), Beijing Key Laboratory of Crop Genetic Improvement, China Agricultural University, Beijing 100193, China

${ }^{2}$ National Plant Gene Research Centre (Beijing), Beijing 100193, China

Full list of author information is available at the end of the article
} 


\section{Background}

$N A C$ genes that encode plant-specific transcription factors influence a diverse set of developmental processes. The NAC family proteins contain a consensus sequence known as the NAC domain (petunia NAM and Arabidopsis ATAF1, ATAF2, and CUC2) [1,2], which is located in the $\mathrm{N}$-terminal region, but their $\mathrm{C}$-terminal sequences are divergent in both length and amino acid sequence [3]. NAC proteins make up a large family, with a total of 109 and 140 predicted proteins identified in Arabidopsis and rice, respectively [4,5]. Members of the NAC family seem to play different roles in plant development. For example, NAM from petunia [1] and CUC2 of Arabidopsis [2] (the first reported NAC genes) are involved in shoot apical meristem (SAM) development. By contrast, the Arabidopsis NAC gene CUC3 has been reported to contribute to the establishment of the cotyledon boundary and the shoot meristem [6]. Another Arabidopsis NAC gene called NAP (NAC-LIKE, activated by $\mathrm{AP} 3 / \mathrm{PI}$ ) has been characterized as the target of two MADS box genes, APETAL3 and PISTILLATA, which control cell division and cell expansion in stamens and petals [7]. AtNAC1 has been characterized as an intermediary in the auxin-signaling pathway that activates genes encoding molecules involved in the specification of lateral root initiation [8]. In addition, NAC proteins have been implicated in defense and abiotic stress responses. Some ATAF subfamily genes, including StNAC from tomato and AtAF1-2 from Arabidopsis, have been shown to be induced by pathogen attack and wounding [9]. More recently, some NAC genes such as BnNAC from Brassica [10], AtNAC072 (RD26), AtNAC019 and AtNAC055 from Arabidopsis [11], and SNAC1 [12] and SNAC2 [13] from rice were found to be involved in the plant's response to various environmental stresses, including drought, salinity, and/or low temperature.

MicroRNAs (miRNAs) are a class of small, non-coding RNAs that regulate gene expression by guiding target mRNA cleavage or translational inhibition [14-16]. In Arabidopsis, miR164 can target five NAC domainencoding mRNAs, including the NAC1, CUC1, CUC2, At5g07680, and At5g61430 mRNAs [17]. NAC1 is able to transmit auxin signals that promote lateral root emergence, and miR164 guides the cleavage of NAC1 mRNA, which is followed by a mechanism to cleave NAC1 mRNA and downregulate auxin signals $[8,18]$. Other groups have independently reported evidence for the miR164mediated regulation of CUC1 [17] and CUC2 [19,20], which have been implicated in meristem development and the separation of aerial organs.

The process of lateral root (LR) development has been extensively studied in flowering plants and gymnosperms, and LRs begin in a specialized cell layer (called the pericycle) in the primary root (PR) [21,22]. In Arabidopsis and most other dicots, LRs are only formed from the pericycle cells that overlay the developing xylem tissue (the xylem pole pericycle). In other species, particularly cereals such as maize, rice and wheat, LRs arise specifically from the phloem pole pericycle, with additional contributions from the endodermis [23,24]. In Arabidopsis, a large body of evidence has indicated that auxin plays a pivotal role in lateral root development. Lateral root initiation begins with auxin-induced IAA14 degradation. This step allows the activation of ARF7 and $A R F 19$ transcription factors, which then activate the expression of $L B D / A S L$ genes. The LBD/ASL proteins in turn activate cell cycle genes and cell patterning genes, allowing the formation of a new lateral root primordium (LRP) $[25,26]$. In addition, auxin activates the transcription of $N A C 1$, which upregulates the expression of two downstream auxin-responsive genes including DBP and AIR3 to stimulate LR initiation [8]. The post-transcriptional and post-translational regulation of NAC1 was also reported as follows: the role of miR164 expression in late auxin response was intended to clear NAC1 mRNA, which would attenuate the auxin signaling that inhibits lateral root development [18]. A RING-finger ubiquitin E3 ligase called SINAT5 promoted NAC1 ubiquitination and its subsequent degradation in order to attenuate the auxin response [27].

In this study, a miR164-targeted NAC domain gene that was designated $Z m N A C 1$ was isolated from maize. It was demonstrated that $Z m N A C 1$ overexpression in Arabidopsis leads to increased number of lateral roots. Further study showed that miR164 is one of the transacting factors that negatively regulates $Z m N A C 1$, resulting in a different $Z m N A C 1$ expression pattern between the two inbred lines 87-1 and Zong3, contributing to a significant difference in the lateral root phenotype between these two lines. Moreover, our analysis also indicated that the promoter variation of maize pri-miR164b in 87-1 and Zong3 might be one in which the dominant cis-element affects the expression of pri-miR164b, leading to differences in mature miR164 expression.

\section{Results}

\section{Identification of putative miR164-regulated NAC genes} in maize

Putative NAC proteins in maize were identified using the conserved NAC domain sequences in a query that was performed by TBLASTN search. Predicted amino acid sequences of the full-length maize cDNA (PlantGDB) were used for the analysis. In this study, a total of 175 putative maize NAC proteins were obtained, and 105 NACs from Arabidopsis were used to construct the polygenetic tree. These NAC proteins could be classified into 3 groups and 14 subgroups on 


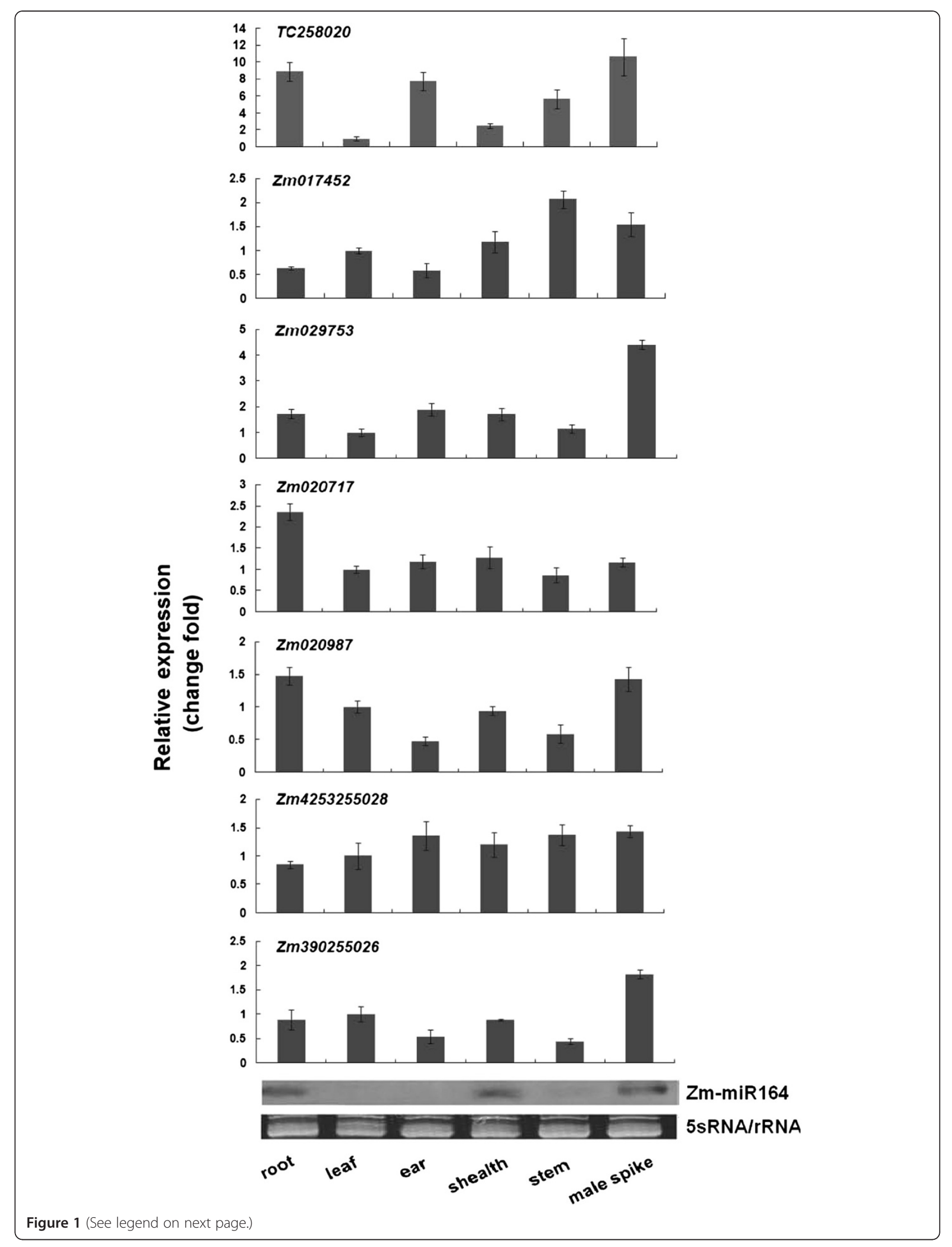


(See figure on previous page.)

Figure 1 Expression analysis of ZmNAC genes and miR164 in various maize tissues, including roots, leaves, ears, leaf sheaths, stems, and male spikes, as determined by real-time PCR. The expression levels of each NAC gene in leaf was chosen as the calibrator. To perform the miR164 expression analysis, an RNA gel blot containing low-molecular-weight RNA (10 $\mu \mathrm{g}$ low molecular weight RNA per lane) was hybridized with an end-labeled DNA oligonucleotide that was complementary to miR164.

the basis of their predicted NAC domain amino acid sequences (Additional file 1). It has been reported that miR164 directs the regulation of 5 target NAC-domain transcription factor mRNAs in Arabidopsis [17]. To obtain putative miRNA-regulated NAC genes from maize, we searched the reverse complementary site for the mature miR164 in the $175 \mathrm{ZmNACs}$. Maize miR164 sequences were identified in http://www.mirbase.org/. Seven $Z m N A C$ genes, TC258020, Zm390255026, Zm029753,

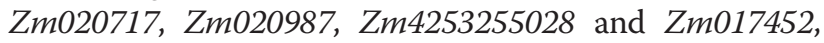
were found to be putative miR164 target genes (Additional file 2), and are shown in pink dots in supplemental Figure 1 (Additional file 1). Among these genes, the amino acid sequence corresponding to three of them, Zm020987, TC258020 and Zm017452, showed high homology to Arabidopsis NAC1 protein (Additional file 1).

\section{Expression of putative miR164-regulated $Z m N A C$ genes}

To assay the expression patterns of seven maize NAC genes (tc258020, Zm017452, Zm029753, Zm020717, Zm020987, Zm4253255028 and Zm390255026) containing the miR164 complementary site, six maize tissues from the roots, leaves, leaf sheaths, male spikes, ears and stems were used for real-time PCR. Because these genes showed a high degree of sequence conservation in the NAC domain, specific PCR primers were designed for the $\mathrm{C}$-terminal region. The results indicated that TC258020 and Zm020717 had higher expression levels in their roots than in other analyzed tissues, whereas Zm020987 and Zm390255026 showed a lower expression level in the ears and stems than in other analyzed tissues (Figure 1). Zm029753 and Zm4253255028 accumulated in all organs and developmental stages (Figure 1). It has recently been proposed that miR164 guides the cleavage of NAC mRNAs in Arabidopsis [18]. An RNA gel blot of maize miRNA164 showed that the miR164 expression levels were higher in roots, leaf sheaths and male spikes than in other organs (Figure 1). This pattern was similar to the pattern of miR164 expression in Arabidopsis, where miR164 accumulated more in its roots and inflorescences than in other tissues [18]. The higher miR164 expression in roots suggested that miR164 might target the NAC gene in roots in vivo.

\section{The $Z m N A C 1$ gene and its expression in maize roots} In Arabidopsis, miR164 directs NAC1 mRNA cleavage, which affects lateral root development [18]. We first sought to identify the putative miR164-targeted $N A C$ genes in maize, which might be involved in lateral root development. Among the seven candidate miR164 target genes, TC258020 encoded a protein of 305 amino acids and shared a high homology with Arabidopsis NAC1, so we named this gene $Z m N A C 1$. The full-length $1657 \mathrm{bp}$ cDNA of ZmNAC1 was obtained by using rapid amplification of cDNA ends (RACE). The $\mathrm{N}$-terminal residues contained the five conserved homologous blocks that characterize the NAC family. The divergent C-terminus displayed no homology to other known proteins. Our analysis detected a putative bipartite nuclear localization signal sequence (NLS) between amino acids 121 and 138 (Additional file 3). Based on the published maize genome sequences, $Z m N A C 1$ was mapped on chromosome 5 and has two introns within its coding region (Figure 2A).

Arabidopsis NAC1 has been shown to play an important role in lateral root development. To determine the putative biological function of $Z m N A C 1$ in maize root development, the inbred lines 87-1 and Zong3 along with a set of RIL (recombination inbred lines derived from the cross between Zong3/87-1) were used, and in this population, either two inbreeds or the RILs showed a significant difference in their lateral root density. The lateral root density of $87-1$ and Zong3 were 4.13 and 6.82 respectively (Figure $2 \mathrm{~B} \mathrm{p}<0.01$ ) and a large amplitude of variation in lateral root density (from 2.3 to 12.6) was observed among the RILs (Additional file 4).

The accumulation of $Z m N A C 1$ transcripts in roots among the inbred lines Zong3, 87-1 and their RILs was determined by real-time PCR, which revealed that $Z m N A C 1$ showed 1.8-fold $(\mathrm{P}<0.05)$ higher expression in Zong3 than in 87-1 (Figure 2C) and had different expression levels among different RIL lines with a maximum of 1.41-fold higher than Zong3 and 3.04-fold lower than 87-1 (Additional file 5). To determine whether the lateral root phenotypes in RIL populations were associated with $Z m N A C 1$ expression level, the correlation coefficient between the lateral root density and the expression levels of $Z m N A C 1$ was calculated. These results showed that the correlation coefficient value reached $0.41 \quad(\mathrm{P}<0.01)$, suggesting that differential $Z m N A C 1$ expression contributed $16.8 \%$ to the lateral root phenotype. Based on these results, we argued that $Z m N A C 1$ played important roles in maize lateral root development and contributes to the lateral root number difference between the inbred lines Zong3 and 87-1. 


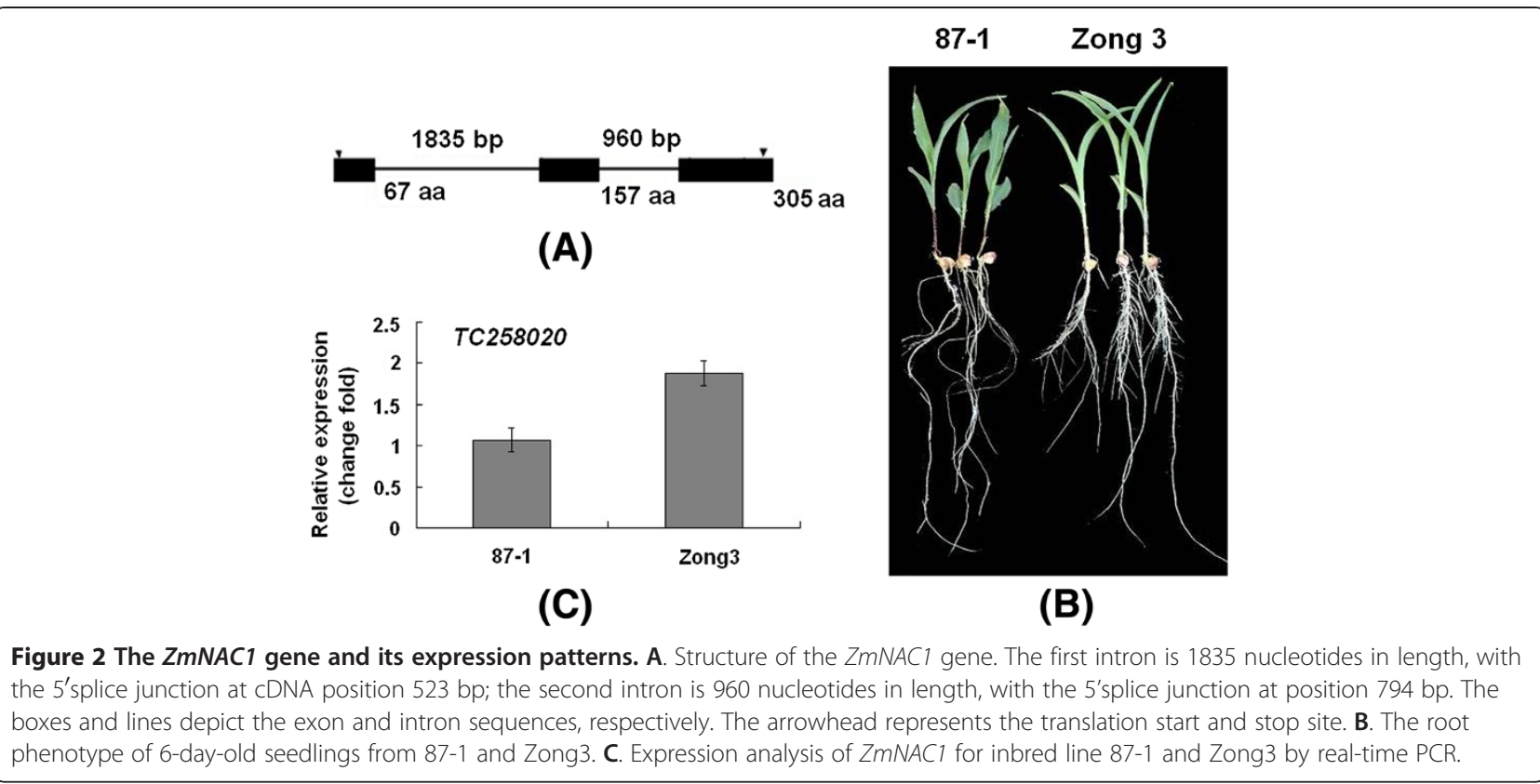

\section{Overexpression of $Z m N A C 1$ in Arabidopsis positively regulated lateral root development}

To further confirm the biological function of ZmNAC1, we generated transgenic Arabidopsis plants that overexpressed the $Z m N A C 1$ gene. The transgenic plants with 35S: ZmNAC1 had a phenotype that displayed earlier and more lateral roots than the wild type. At 9 days after germination, the seedlings of 35S: ZmNAC1 transgenic lines (but not the wild type seedlings) developed lateral roots. At 11 days after germination, we measured the number of lateral roots per centimeter of primary root in 35S: ZmNAC1 and wild type plants, and the results showed that the lateral root density in the overexpression line and the wild type reached $2.45 \pm 0.27$ and $0.92 \pm 0.18$, respectively, with a significant difference between them $(\mathrm{n}=18, \mathrm{P}<0.01, t$-test) (Figure 3$)$. However, there was no difference in phenotype in the growth of the above-ground portion between the wild type and transgenic plants.

\section{ZmNAC1 allelic expression between maize hybrids and parents}

Gene regulation involves numerous molecular interactions. In general, both cis-regulatory elements and transregulatory factors can play important roles. To determine whether the expression of $Z m N A C 1$ is regulated by a cis-, trans-acting or both mechanism, we compared the allelespecific expression of ZmNAC1 in Zong3, 87-1 and their hybrid (Zong3/87-1), which was used as an excellent system to assay allele-specific expression. The two alleles from Zong3's female parent and 87-1 's male parent were compared in the hybrid Zong3/87-1 and were found to be equally affected by genetic background or environmental factors. The allele from Zong3 had a 4 bp insertion in the 5/UTR region compared to the allele from 87-1, which made it possible to distinguish the alleles from the two inbred lines and their hybrid; therefore, the parental transcript accumulation in the two inbred lines and the hybrid was examined using allele-specific RT-PCR analysis (Figure 4).

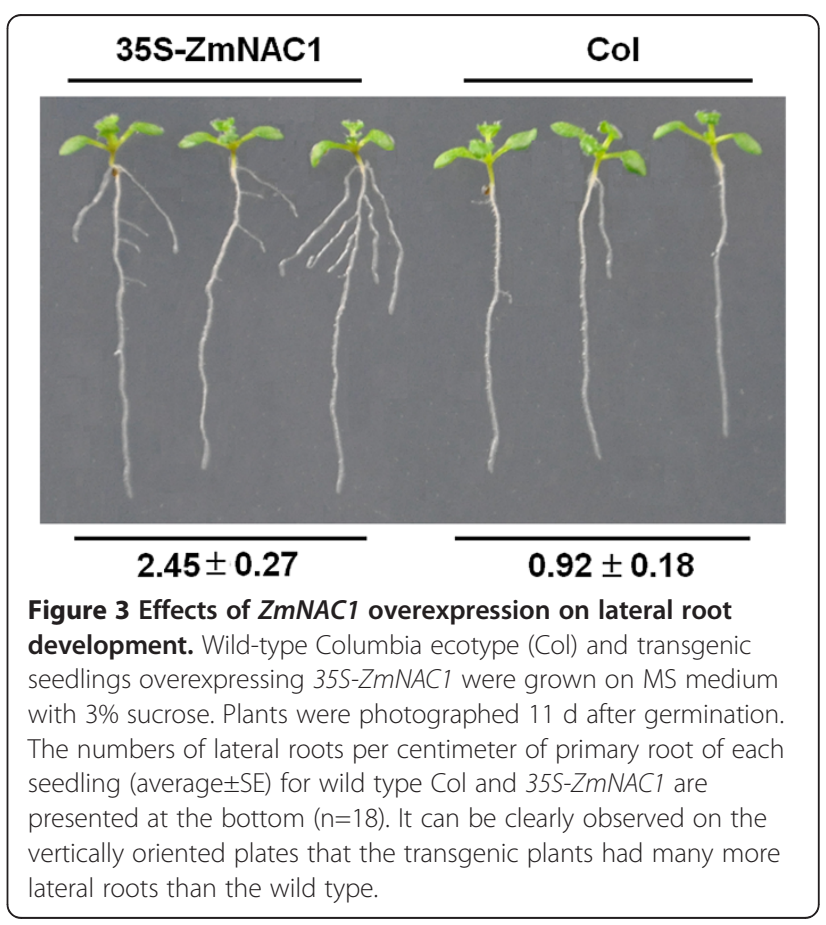




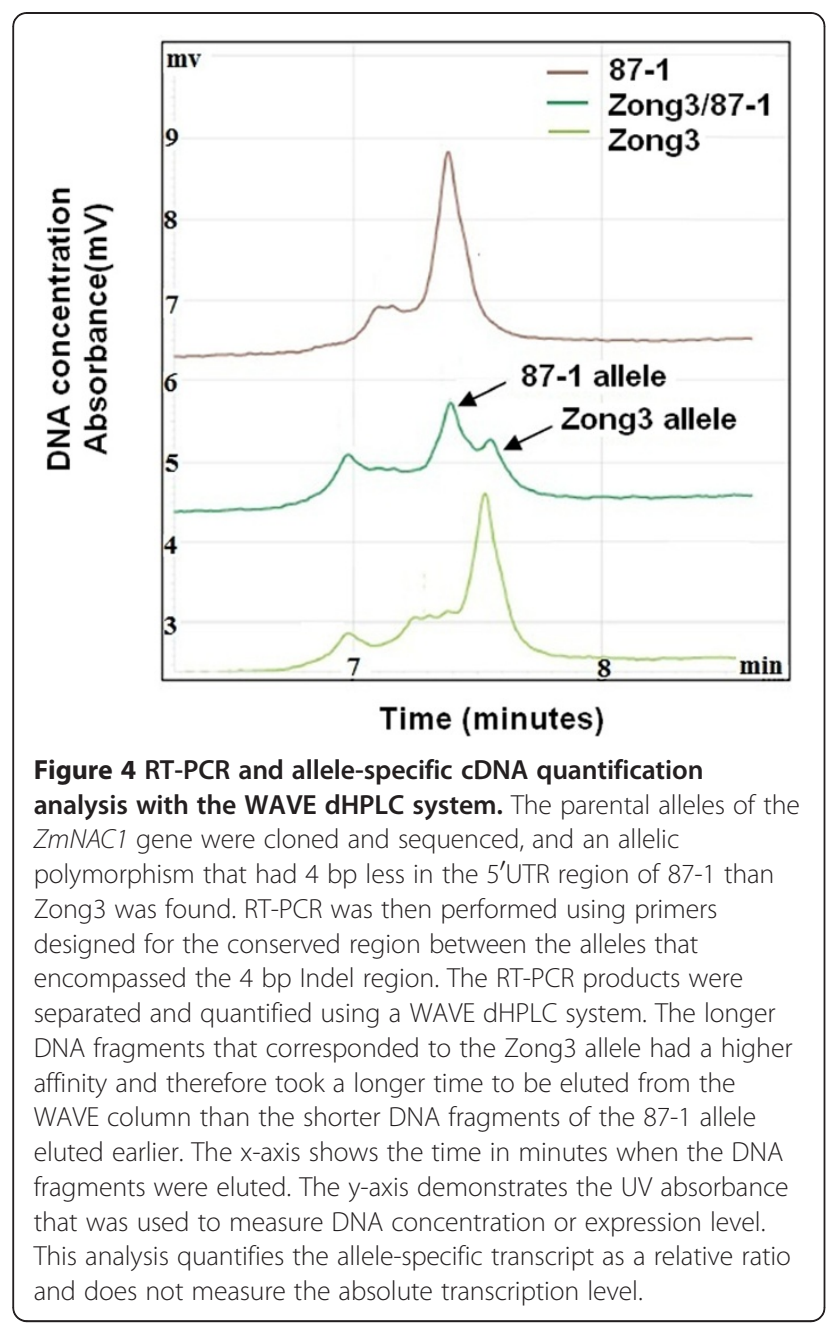

Different types of regulatory divergence can be detected experimentally by assaying the allele-specific gene expression in the two parents and the hybrid. When the alleles differ in their expression to the same extent in the parental plants as in the hybrids, then cis-acting genetic differences may be inferred [28,29]. When the alleles differ in their expression to a larger extent in the parental species than in the hybrids, then transacting genetic differences may be inferred. The WAVE dHPLC system was used to calculate the P-ratio, which is the ratio of allelic expression in the two parental lines, as well as the $\mathrm{H}$-ratio, which is the ratio of alleles from the two parents in the hybrid. Then, we examined whether two ZmNAC1 alleles showed (1) differential expression in the parents (P-ratio $\neq 1),(2)$ differential expression in the hybrid (H-ratio $\neq 1$ ), or (3) a difference in the ratio of allelic expression in the parental lines relative to that of the hybrid (P-ratio $\neq \mathrm{H}$-ratio). Our analysis showed that the H-Ratio was $1.15 \pm 0.06$ (not significantly different from 1.0) (Table 1), indicating that there was no difference in cis-regulatory elements
Table 1 Allele-specific transcript ratio of ZmNAC1 in hybrids and parents (CDNA-RT PCR)

\begin{tabular}{|c|c|c|c|c|c|}
\hline \multirow[t]{2}{*}{$87-1$} & \multirow[t]{2}{*}{ Zong3 } & \multirow{2}{*}{$\begin{array}{l}\text { P Allelic } \\
\text { ratio 87- } \\
\text { 1: Zong3 }\end{array}$} & \multicolumn{2}{|c|}{ Zong3/87-1 } & \multirow{2}{*}{$\begin{array}{l}\text { H Allelic } \\
\text { ratio 87- } \\
\text { 1: Zong3 }\end{array}$} \\
\hline & & & 87-1 allele & Zong3allele & \\
\hline & $2.21(0.05)$ & $0.58(0.01)^{*}$ & $1.69(0.03)$ & 1.48( & $1.15(0.06)$ \\
\hline
\end{tabular}

The allelic transcript ratios (87-1: Zong3) of parents and hybrids were compared with an expected ratio indicating an equal allelic expression of 1.0. The mean, standard error (in parenthesis), and $\mathrm{P}$ values in the $t$ test were based on three biological replicates. ${ }^{*} \mathrm{P}<0.05$.

between alleles from $87-1$ and Zong3. The P-Ratio (87-1/Zong3) was $0.58 \pm 0.01$, which is significantly different from $1.0(\mathrm{P}<0.05)$ and unequal to the $\mathrm{H}$ Ratio ( $\mathrm{P}$ ratio $\neq \mathrm{H}$ ratio) (Table 1 ), indicating that there was a change only in the trans-regulatory elements. These findings suggested that the trans-regulatory elements were the dominant mediator of the differential expression of ZmNAC1 between the two Zong3 and 87-1.

\section{miR164 as the trans-acting factor that regulates expression of $\mathrm{ZmNAC1}$}

We assessed whether maize miR164 is the trans-acting factor that can direct the cleavage of $Z m N A C 1$, and demonstrated that miR164 can direct ZmNAC1 mRNA cleavage, by using a modified RNA ligase-mediated $5^{\prime}$ rapid amplification of cDNA ends (5'-RACE) protocol. RNA sequences with 5 ' termini corresponding to the center of the miR164 complementary site were consistently detected as the product of miRNA processing. Sequencing analysis of 8 independent clones produced identical results and placed the $5^{\prime}$ end of the cleaved fragment at nucleotide 991 of the $Z m N A C 1$ mRNA. This nucleotide position was located in the middle of the miR164/NAC mRNA complementary region, indicating that ZmNAC1 mRNA was the in vivo miR164 cleavage target (Figure 5A and B).

We then investigated the expression of mature miR164 to determine whether miR164, which can act as the transacting regulator of $Z m N A C 1$, also showed differential expression between 87-1 and Zong3. Northern blot analysis showed that the mature miR164 had higher expression levels in 87-1 than in Zong3 (Figure 5C), which was the opposite of the ZmNAC1 expression pattern in the two inbred lines.

MiR164 was potentially transcribed from 8 loci, specifically from miR164a to miR164h, in maize. The mature miR164 from these loci differed by one or two nucleotides at the 3 ' end. We designed specific primers to amplify the 8 precursors, and only miR164b and miR164d had a higher expression level in the roots than in other tissues. Because the oligonucleotide probe used in the RNA gel blot cannot discriminate among these eight transcripts, we used gene-specific RT-PCR to analyze pri-miR164 expression. The results revealed that 


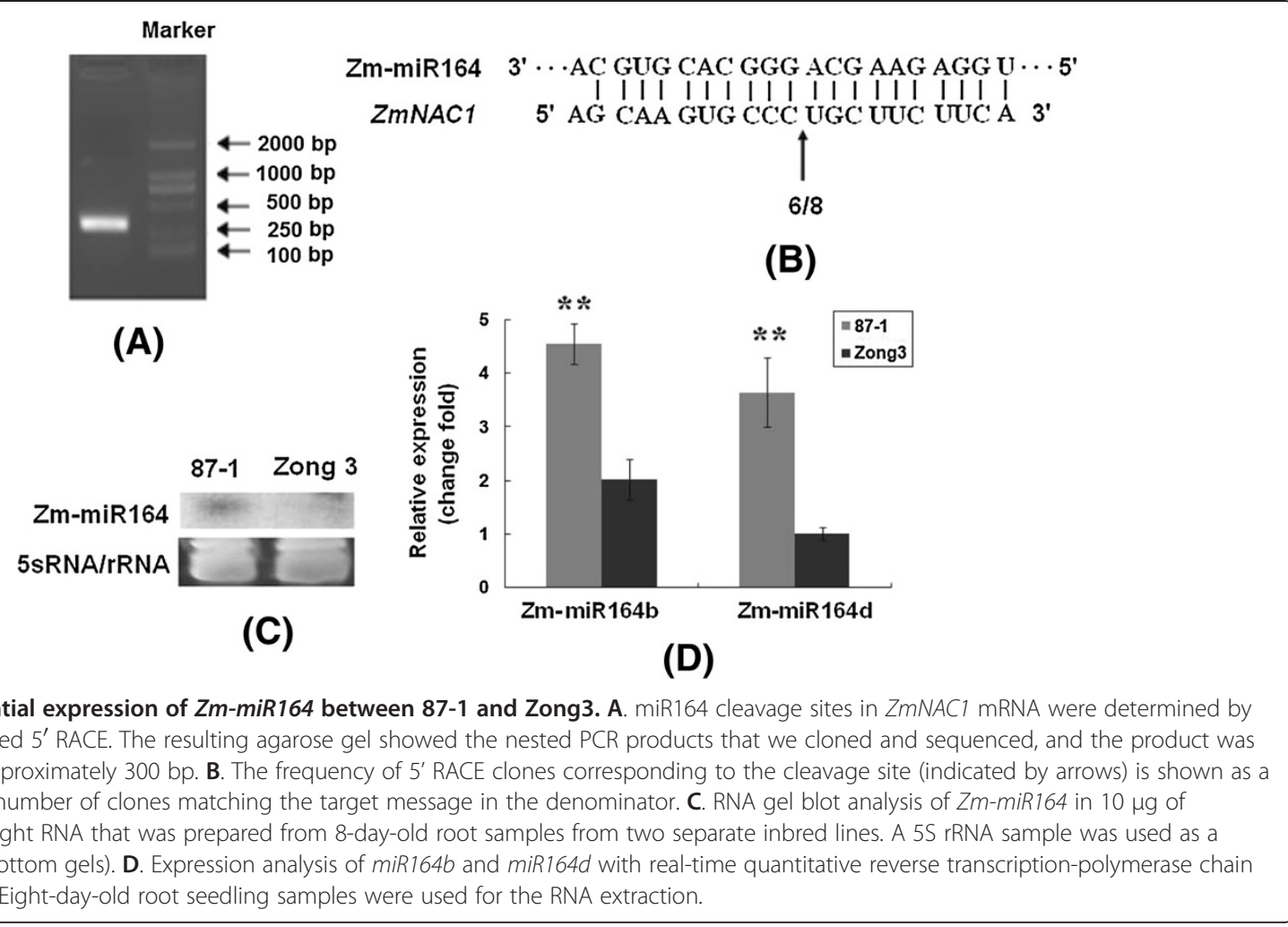

pri-miR164b (primary miRNA) and pri-miR164d showed 2.4-fold and 3.6-fold higher expression levels in 87-1 than in Zong3 $(\mathrm{P}<0.01)$, respectively (Figure $5 \mathrm{D})$, suggesting that a higher expression of miR164 precursors may contribute to the higher expression of mature miR164s in 87-1.

\section{ZmmiR164b allelic expression between maize hybrids and parents}

The WAVE HPLC system was used to determine whether the differential expression of ZmmiR164 precursors was regulated by a cis-or trans-acting mechanism. First, the full-length cDNA of the miR164b and miR164d precursors was obtained by $5 / \mathrm{RACE}$, and the subsequent sequence analysis indicated that the single transcription start sites for pri-miR164b and pri-miR164d were 105 and 126 nucleotides upstream from the start of the mature miR164, respectively. Based on the full-length cDNA, the alleles from Zong3 and 87-1 were amplified and sequenced. The ZmmiR164b allele from Zong3 contained an 8 bp insertion in comparison to that of 87-1; this insert did not have an effect on the formation of the
pre-miR164 secondary structure (Additional file 6). The allelic transcript ratio between the two parents ( $\mathrm{P}$ value) and in the hybrid ( $\mathrm{H}$ value) was determined by HPLC (Figure 6), and the results showed that the $\mathrm{P}$ ratio (87-1/Zong3) and $\mathrm{H}$ ratio (87-1/Zong3) could reach up to $2.39 \pm 0.03$ and $2.26 \pm 0.45$, respectively (Table 2 ). The $P$ ratio $=\mathrm{H}$ ratio $\neq 1$ pattern indicated that a cis-element was involved in the different expression patterns of pri-miR164b transcripts in the two inbred lines. Therefore, the sequence difference between the promoters of ZmmiR164b in Zong3 and 87-1 could be responsible for the differential expression of ZmmiR164b. For ZmmiR164d, the two alleles from the two inbred lines only differed at one nucleotide, so we could not detect the allelic expression with the WAVE dHPLC system.

\section{Promoters of Zm-miR164b from inbred line 87-1 showed higher activity}

To provide evidence for the cis-regulation of the miR164 precursor, we isolated a $2.6 \mathrm{~kb}$ region upstream of the miR164b transcription start site and then determined the activity of the promoters from the two inbred lines $87-1$

Table 2 Allele-specific transcript ratio of Zm-miR164b in hybrids and parents (CDNA-RT PCR)

\begin{tabular}{llllll}
\hline 87-1 & Zong3 & P Allelic ratio 87-1: Zong3 & \multicolumn{2}{c}{ Zong3/87-1 } & H Allelic ratio 87-1: Zong3 \\
\cline { 3 - 5 } & & & 87-1 allele & Zong3 allele & \\
\hline $4.41(0.02)$ & $1.85(0.03)$ & $2.39(0.03)^{* *}$ & $3.30(0.27)$ & $1.48(0.17)$ & $2.26(0.45)^{* *}$ \\
\hline
\end{tabular}

The allelic transcript ratio (87-1: Zong3) was significantly different from 1.0 , with ${ }^{*} \mathrm{P}<0.01$, whereas the $\mathrm{P}$ and $\mathrm{H}$ ratios were not significantly different. 


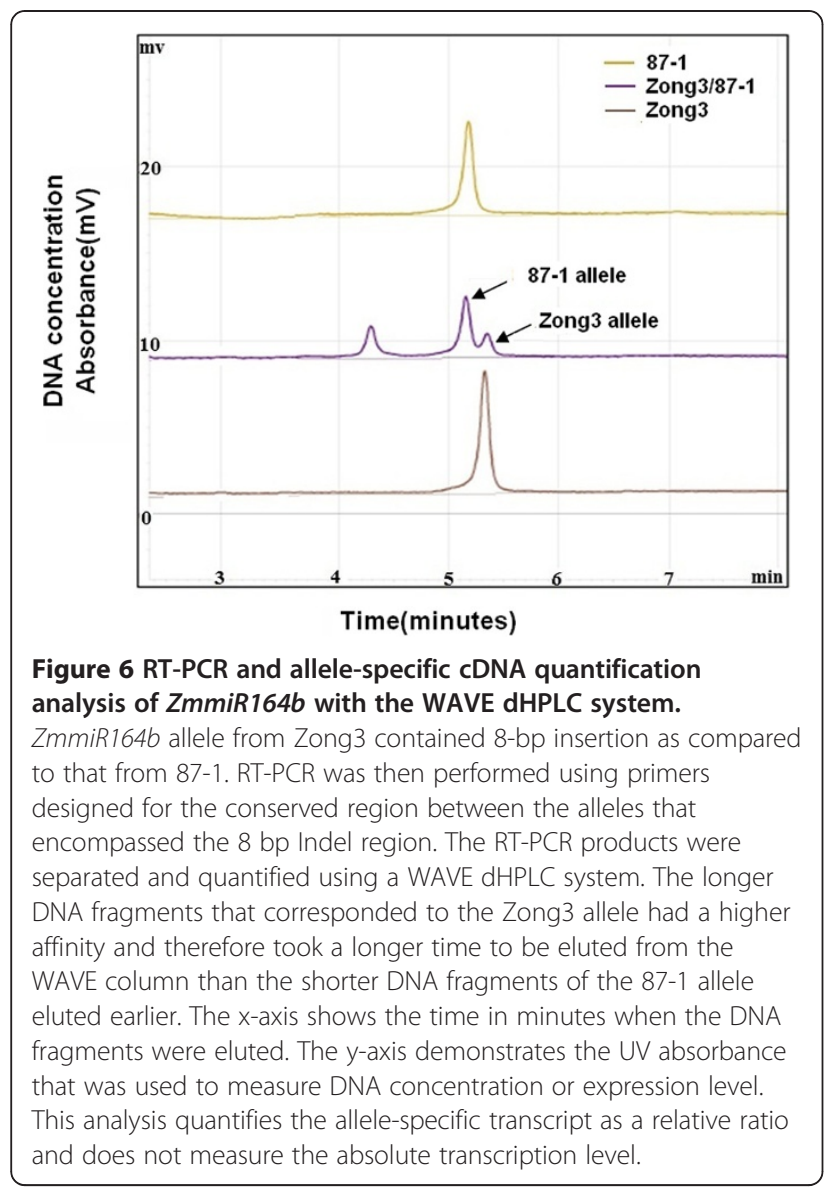

and Zong3. Sequence analysis revealed that the promoters from these two lines exhibited $71.07 \%$ nucleotide identity for $m i R 164 b$. Based on the sequence polymorphism, specific primers were designed to differentiate the promoters from the two inbred lines.

First, we tested whether ZmmiR164b showed higher transcription levels in RIL plants that contained the promoter from 87-1 than RIL plants that contained the Zong3 promoter. The promoter polymorphism was detected in Zong3, 87-1 and their 40 RILs, among which 19 lines had the same promoter as 87-1 and 21 lines had the same promoter as Zong3. We further examined the expression level of ZmmiR164b among these lines and found that the RILs with the 87-1 promoter had a higher expression level, with 4.37 -fold $(\mathrm{P}<0.01)$ on average compared with the lines with Zong3 promoters (Figure 7A). These findings strongly suggest that the cis-element of the miR164 promoter is the main contributor to the differential expression of pri-miR164, and it could be argued that other elements might also be involved in the regulation of pri-miR164 expression.

To further investigate whether the ZmmiR164b promoter from 87-1 showed higher activity in vitro than that from Zong3, we designed a promoter: GUS reporter assay, including $87 \mathrm{p}-Z m m i R 164 b$ : GUS (the promoter of miR164b from 87-1) and Zong3p-ZmmiR164b: GUS (the promoter of miR164b from Zong3). Tobacco leaves were infiltrated with Agrobacterium that harbored these constructs, and GUS activity expression was analyzed by spectrophotometric assays. We also transformed tobacco leaves with a GFP vector to normalize the transformation efficiency. Our results showed that GUS activity that was driven by the promoter from 87-1was significantly higher than that driven by the promoter from Zong3 and by the background (Figure 7B), which strongly suggested that the different promoter activities of pri-miR164 resulted in the diversity of pri-mir164 transcript levels that was found between the two inbred lines, which may have led to the difference in mature miR164 expression between 87-1 and Zong3. In addition, the correlation coefficient between the expression levels of $Z m m i R 164 b$ and the lateral root numbers among the RILs was also calculated, but no significant correlation was observed (Additional file 7).

\section{Discussion}

\section{ZmNAC1 played an important role in lateral} root development

We isolated and characterized $Z m N A C 1$, which is a member of the NAC-domain gene family and the first NAC gene shown to be involved in maize lateral root development. We demonstrated that ZmNAC1has high amino acid similarity to a homologous gene, NAC1, in Arabidopsis, which has also been reported to play an important role in lateral root development. In contrast to the other members of its family, ZmNAC1 showed higher expression levels in the roots than in other tissues. Moreover, $Z m N A C 1$ was more highly expressed in the roots of inbred Zong3 than inbred 87-1, and inbred Zong3 had more lateral roots than inbred 87-1. The RIL populations derived from the Zong3/87-1 hybrid showed significant differences in lateral root numbers and in ZmNAC1 expression. There was a significant correlation (correlation coefficient value reached $0.41, \mathrm{P}<0.01$ ) between the expression levels of $Z m N A C 1$ and the lateral root number phenotype of the RILs, illustrating that $Z m N A C 1$ is important for maize lateral root development. Overexpression of ZmNAC1 in Arabidopsis resulted in a higher number of lateral roots than in the wild type, whereas no other dramatic phenotype change was detected in transgenic plants. However, once the lateral roots initiated in the transgenic plants, no further alterations in root development occurred. These results suggest that $Z m N A C 1$ is specifically involved in the control of lateral root initiation. The phenotype of transgenic plants that overexpress $Z m N A C 1$ was consistent with $N A C 1$ having its main function in the roots, as only lateral root development was affected. 


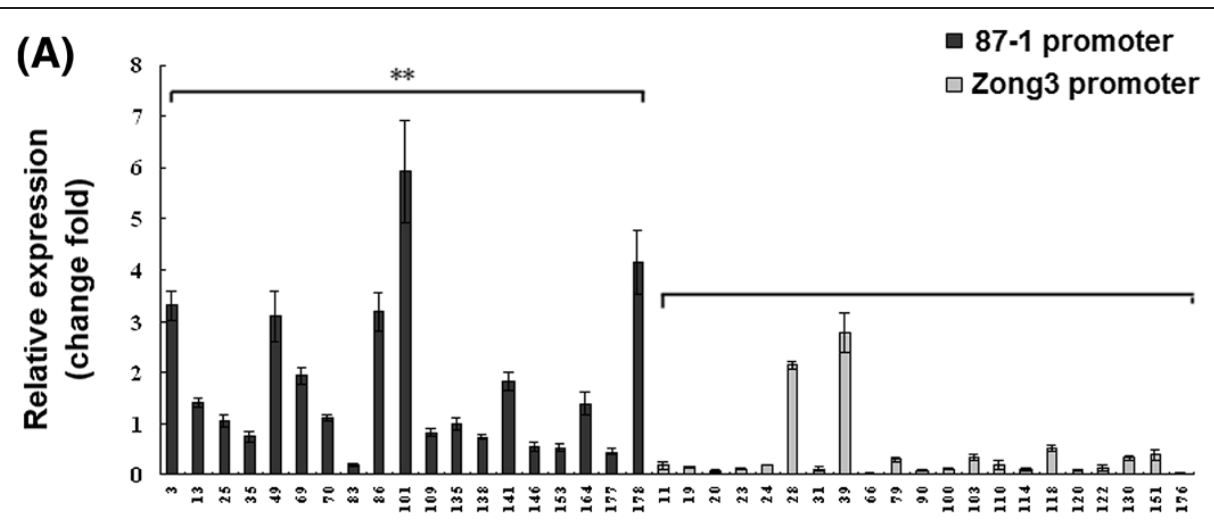

RIL population

(B)

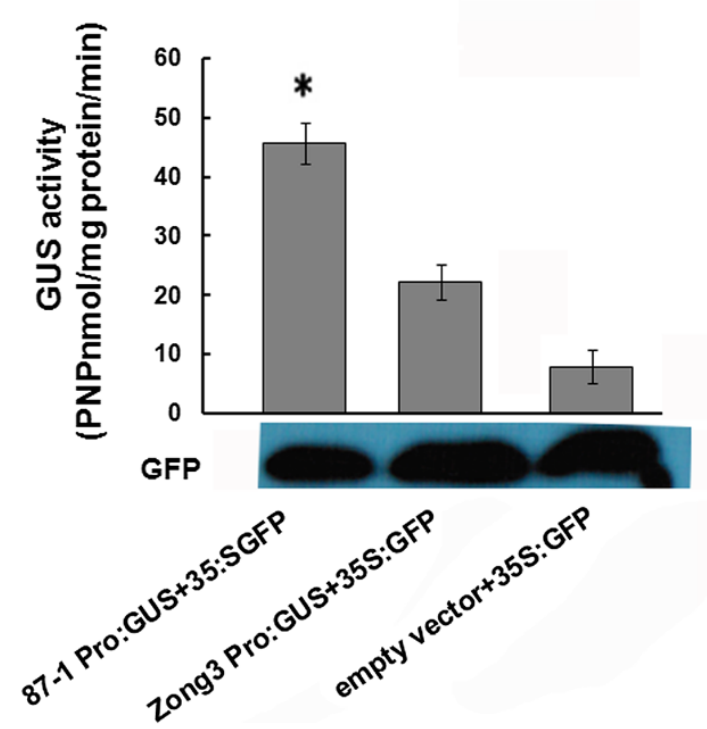

Figure 7 Analysis of pri-miR164b promoter activity. A. Expression analysis of Zm-miR164b in the RIL population. The darker columns were the RIL lines that contained the same promoter with 87-1, while the lighter ones had the same promoter with Zong3. ** represented significant difference between RIL plants containing the promoter from 87-1 and RIL plants containing the Zong3 promoter. B. GUS activity (nmole PNP/mg protein/min) as analysis driven by different promoters. GUS activity that was driven by the Zm-miR164b promoter from $87-1$ and Zong3 in the tobacco leaf tissues was expressed as p-nitrophenol (PNP) nmole $\mathrm{mg}^{-1}$ protein $\mathrm{min}^{-1}$. The averages of the GUS activity and the standard deviations of the experiment were derived from three independent assays of tobacco leaf extracts. The significance of GUS activity differences relative to empty vector values as determined by Student's $t$-test analysis is indicated here with asterisks $(* P<0.05)$.

Nonetheless, we cannot exclude the possibility that $Z m N A C 1$ plays roles in other developmental pathways. ZmNAC1 also showed a higher expression level in the ears, stems and male spikes than in the leaves, so we speculated that ZmNAC1 might also be involved in the branching development of ears and male spikes.

\section{miR164-mediated ZmNAC1 mRNA cleavage in vivo}

Plant miRNAs have been implicated in the control of various developmental processes, including leaf development [30-32], flower development [33] and lateral root development [18]. In Arabidopsis, miR164 has been predicted to target $5 \mathrm{NAC}$-domain transcripts: NAC1,
CUC1, CUC2, At5g07680 and At5g61430 [17]. Among these targets, CUC1 and CUC2 contribute to embryonic and floral development, and NAC1 plays important roles in lateral root development. Here we provide evidence showing that miR164 directs ZmNAC1 mRNA cleavage in vivo at the $11^{\text {th }}$ nucleotide of the complementary miR164 binding site, and this cleavage was conserved between maize and Arabidopsis. In addition, ZmmiR164 showed higher expression levels in inbred 87-1 than in Zong3, which was the opposite of the expression pattern found for $Z m N A C 1$, suggesting that miR164 negatively regulates $Z m N A C 1$. These findings confirmed that this conserved miRNA can regulate a target gene in a conserved pathway throughout evolution. 
miR164 as a trans-acting factor contributed to the differential expression of $Z m N A C 1$ between

\section{7-1 and Zong3}

The results of the allelic variation analysis for ZmNAC1 in 87-1, Zong3, and hybrid Zong3/87-1 maize showed that the trans-acting factor, and not the cis-element, was most likely the major factor underlying the differential expression of ZmNAC1 between 87-1 and Zong3. We further isolated and compared the $1 \mathrm{~kb} Z m N A C 1$ promoter sequences between the inbred lines 87-1 and Zong3, and no sequence difference was found except for one SNP (Additional file 8). Based on the ZmNAC1 mRNA cleavage that was directed by miR164, we consider miR164 to be one of the post-transcriptional trans-acting factors that regulates $Z m N A C 1$ expression. However, no significant negative correlation was detected between the expression levels of ZmmiR164b and ZmNAC1 in the RIL population, suggesting that the expression of $Z m N A C 1$ is also regulated by other genes, as observed in Arabidopsis. For example, Xie reported that the F-box protein TIR1 is likely involved in ubiquitin-mediated proteolysis of regulatory proteins that are required for an auxin response and can induce the expression of NAC1 through auxin signals [8].

Further study revealed that both the mature miR164 and the precursor pri-miR164b were expressed at higher levels in 87-1 than in Zong3 and that the promoter of ZmmiR164b from 87-1 showed higher activity in vivo and in vitro than that of Zong3, which might lead to the higher expression level of miR164 in 87-1 than in Zong3. It has been reported that Arabidopsis miR164 negatively regulates lateral root development, showing a strict inverse correlation between changes in the miR164 level and the NAC1 mRNA levels. Mutant plants that were defective in miRNA biogenesis showed a higher level of NAC1 mRNA and more lateral roots. Conditional overexpression of miRNA164 decreased NAC1 mRNA and lateral root numbers. Based on our results, it is possible to improve the root development in maize by altering the miR164 pathway.

Arabidopsis NAC1 has been shown to be a transcriptional activator in auxin-induced lateral root initiation. This study shows that $Z m N A C 1$ also plays an important role in maize lateral root development and that $Z m N A C 1$ expression is regulated at the post-transcriptional level by miR164. Overall, our data suggest that in 87-1 maize (which has fewer lateral roots than Zong3), the miR164b promoter has higher activity than in Zong3, leading to a higher expression level of mature miR164, which then downregulates $Z m N A C 1$ expression at the posttranscriptional level. This pathway might contribute to the smaller lateral root numbers in 87-1. By contrast, both pri-miR164b and mature miR164 had a lower expression level in inbred Zong3 maize than in
87-1 maize, leading to a higher expression of ZmNAC1, thus contributing to greater numbers of lateral roots. It should be noted that no significant negative correlation was detected between the expression levels of ZmmiR164b and lateral root numbers in the RIL population, which revealed the complexity of ZmmiR164 and its regulation of lateral root development in maize.

\section{Conclusion}

Arabidopsis NAC1 is a transcriptional activator in auxininduced lateral root initiation. Our study shows that the maize homologue, ZmNAC1, also plays an important role in lateral root development in maize. Our study then extends the research by showing that ZmNAC1 expression is regulated at the post-transcriptional level by maize miRNA164. Overall, our data suggest that the miR164b promoter showed higher activity in inbred 87-1 maize than in Zong3 maize, leading to higher expression of mature miR164, which down-regulated ZmNAC1 expression at the post-transcriptional level. This pathway might contribute to 87-1 having fewer lateral root numbers than Zong3.

\section{Methods}

\section{Plant materials and growth condition}

The maize (Zea mays L) inbred lines 87-1 and Zong3, the hybrid line Zong3/87-1, and 40 recombinant inbred lines (RIL) that were derived from the hybrid Zong3/ 87-1 were used for this study. For phenotypic analysis of lateral root numbers, seed germination was initiated by soaking in distilled water in a Petri dish for $12 \mathrm{~h}$ at room temperature. Seeds were then placed between layers of moist paper towels at $30^{\circ} \mathrm{C}$ for $24 \mathrm{~h}$ and transplanted into pots. Seeds were cultivated in vermiculite with no additional fertilizer and grown in a growth chamber at a relative humidity of $40-60 \%$ and a $26 / 24^{\circ} \mathrm{C}$ day and night temperature under a 16-h-light/8-h-dark photoperiod. Eight individuals were planted for each genotype, and half of them were collected for gene expression analysis (the rest were used for the investigation of lateral root density). All of the root samples were collected at 8 days after germination between 8:00 a.m. and 9:00 a.m., and root samples were collected carefully and cleaned with water without causing any injury. Lateral root numbers in primary root were counted manually, and the number was divided by the length of primary root to calculate the parameter for lateral root density [34]. Three biological replicates were performed for both gene expression and phenotypic analysis of lateral roots. For tissue expression pattern analysis, the root, leaf, sheath in the V3 stage, spike in the V12 stage, and stem in the V9 stage were collected for real-time PCR and Northern blot analysis.

The Arabidopsis thaliana Col-0 ecotype was used for transformation. Seeds were germinated after $3 \mathrm{~d}$ of 
vernalization on Murashige and Skoog (MS) medium at $4^{\circ} \mathrm{C}$. Plants that were intended for transformation were grown under continuous light $\left(150 \mathrm{mE} / \mathrm{m}^{2}\right.$ per s) at $22^{\circ} \mathrm{C}$ in a greenhouse.

\section{Gene expression analysis}

For Northern blot hybridization, total RNA was isolated using Trizol (Invitrogen, Carlsbad, CA, USA) according to the manufacturer's instructions. Low molecular weight RNA was enriched with $0.5 \mathrm{M} \mathrm{NaCl}$ and 10\% PEG 8000 precipitation. Ten $\mu \mathrm{g}$ of low molecular weight RNA was loaded per lane, resolved on a denaturing 15\% polyacrylamide gel, and electrophoretically transferred to Hybond- $\mathrm{N}^{+}$membranes (Amersham Biosciences, Buckinghamshire, UK). Membranes were UV-crosslinked and baked for $2 \mathrm{~h}$ at $80^{\circ} \mathrm{C}$. DNA oligonucleotides that were complementary to miR164 were end-labeled with $\gamma$-32P-ATP using T4 polynucleotide kinase (TaKaRa, Dalian, China). Membranes were pre-hybridized for more than $8 \mathrm{~h}$ and then hybridized overnight using Church buffer at $38^{\circ} \mathrm{C}$. Blots were washed three times (twice with $2 \times$ SSC $+1 \%$ SDS and once with $1 \times$ SSC $+0.5 \%$ SDS) at $50^{\circ} \mathrm{C}$. The membranes were briefly air-dried and then exposed to X-ray films for autoradiography at $-80^{\circ} \mathrm{C}$.

For the real-time PCR analysis, total RNA was isolated by using Trizol (Invitrogen, USA) according to the manufacturer's instructions and treated with RNase-free DNase I (Promega, Madison, USA). Two $\mu \mathrm{g}$ of total RNA from each sample was used for first-strand cDNA synthesis in $20 \mu \mathrm{L}$ reactions containing $50 \mathrm{mM}$ Tris$\mathrm{HCl}$ (pH 8.3), $75 \mathrm{mM} \mathrm{KCl,} 3 \mathrm{mM} \mathrm{MgCl}, 10 \mathrm{mM} \mathrm{DTT}$, $50 \mu \mathrm{M}$ dNTPs, $200 \mathrm{U}$ M-MLV reverse transcriptase (Promega, Madison, USA) and 50 pmol T15 oligonucleotides. Reverse transcription was performed at $37^{\circ} \mathrm{C}$ for $60 \mathrm{~min}$ with a final denaturation at $95^{\circ} \mathrm{C}$ for $5 \mathrm{~min}$. Gene-specific RT-qPCR primers for 7 putative miR164 targets were designed according to the EST sequences. A $250 \mathrm{bp} \beta$-actin gene fragment was amplified as a positive control using the primer pair 5'-TGGCATTGTCAA CAACTGG-3' and 5'-TCATTAGGTGGTCGGTGAGG-3'. PCR reactions were performed in a volume of $20 \mu \mathrm{L}$ containing $10 \mathrm{pmol}$ primers, $10 \mathrm{mmol} / \mathrm{L}$ Tris- $\mathrm{HCl}$ (pH8.5), 50 $\mathrm{mmol} / \mathrm{L} \mathrm{KCl}, 2 \mathrm{mmol} / \mathrm{L} \mathrm{MgCl}_{2}, 0.4 \mu \mathrm{L}$ DMSO, $200 \mathrm{mmol} / \mathrm{L}$ dNTPs, 1 U Taq DNA Polymerase (TaKaRa, Dalian), and $0.5 \mu \mathrm{L}$ SYBR GREEN I. The following PCR amplification protocol was used: $95^{\circ} \mathrm{C}(3 \mathrm{~min})$ and 40 cycles of amplification cycle $\left(95^{\circ} \mathrm{C}(30 \mathrm{~s}), 55^{\circ} \mathrm{C}(30 \mathrm{~s})\right.$,and $\left.72^{\circ} \mathrm{C}(1 \mathrm{~min})\right)$ using an Opticon PTC200 system (MJ Research, Waltham, MA, USA). All reactions were run in triplicate, and no template and no reverse transcription controls were included. Quantification results were expressed in terms of the cycle threshold $(\mathrm{CT})$ values according to the baseline, which was adjusted to 0.04. The comparative CT method (PE Applied Biosystems, Foster City, CA, USA) was used to quantify gene expression in comparison with actin. In brief, the $\mathrm{CT}$ values were averaged for each triplicate. The differences between the mean CT value of a specific gene and that of $\beta$-actin was calculated as $\Delta C T^{\text {sample }}=\mathrm{CT}^{\text {gene }}-\mathrm{CT}^{\beta \text {-actin }}$. In the final results, the sample's relative expression level was determined by $2^{-\Delta C t}$ method. Statistical significance was tested using Student's $t$-test $(\mathrm{P}<0.05)$.

\section{Mapping of the miRNA-guided cleavage site}

The GeneRacer Kit (Invitrogen USA) was used for the RACE assay according to the manufacturer's instructions. Total RNA was extracted from the roots of 87-1 seedlings, and Poly(A)mRNA was purified and ligated to the RLM-RACE 5'RACE RNA Oligo adaptor (5'-CGACUGGAGCACGAGGACACUGACAUGGACU GAAGGAGUAGAAA-3'). The oligo (dT) (15-mer) primer was used for cDNA synthesis with reverse transcriptase, and the resultant cDNA was used for the first round of nested PCR using the 5' RACE primer 5'-CGACTGGAGCACGAGGACACTGA-3' together with ZmNAC1 gene-specific primer 5'ACCCAAGCCTCT TGTAGCACTCATC-3'. The 5' RACE nested primer 5'-GGACACTGACATGGACTGAAGGAGAT-3' and the gene-specific nested primer 5'-GTCGAGGCATTTCG ATCCGCATC-3' were used for the second round of nested PCR. Gel-purified PCR products were cloned into the pGEM-T Easy Vector (Promega) and sequenced.

\section{Transformation vectors and construction of transgenic plants}

For the transgenic Arabidopsis plants, constructs were made in the binary vector pCAMBIASuper1300. For the plasmid super-p: $Z m N A C 1$, the forward primer (5'-GCTCTAGACGCAGAAGTTGACCACGTAC-3') (the underlined sequence is the $\mathrm{XbaI}$ site) and the reverse primer (5'-GGGGTACCATCCATCCTGTTATCGTCGAG-3') (the underlined sequence is the KpnI site) were designed to introduce XbaI and KpnI sites, and Zong3 root cDNA samples were used to amplify a $1463 \mathrm{bp}$ cDNA from $Z m N A C 1$. The construct was transformed into Agrobacterium GV3101. Six-week-old Arabidopsis plants were transformed via Agrobacterium-mediated transformation by the floral-dip method [35]. Transgenic plants were selected on 1/2 MS medium (Gibco BRL, Grand Island, NY, USA) containing hygromycin B. T3 generation was used for further experiments.

\section{Agrobacterium-mediated transient expression assay and GUS activity assay}

The miR164b promoters from the inbred lines 87-1 and Zong3 were ligated into the Gateway pDONR 211Vector (Invitrogen USA), and then the vector miR164b-87- 
1promoter:: GUS and miR164b-Zong3promoter::GUS construct made according to the manufacturer's instructions. Two primers in different orientations (5'-CAA AAAAGCAGGCTGTGATTGACGACAACATGAACA AATC-3',5'-ACAAGA AAGCTG GGTCG CAATTCTCG AATTCACCTTC-3'; the underlined sequence is the attB1 and attB2 site) were used to amplify the promoter sequences from 87-1 and Zong3 in separate DNA samples. Agrobacterium GV3101 that harbored each of the promoter:GUS constructs was grown on yeast extract peptone medium (10 g yeast extract, $10 \mathrm{~g}$ Bacto peptone, $5 \mathrm{~g}$ $\mathrm{NaCl}$, and $15 \mathrm{~g}$ agar/l) supplemented with rifampicin $(60 \mu \mathrm{g} / \mathrm{mL})$, kanamycin $(50 \mu \mathrm{g} / \mathrm{mL})$ and spectinomycin $(100 \mu \mathrm{g} / \mathrm{mL})$. Agrobacterium was cultured at $28^{\circ} \mathrm{C}$ and harvested by centrifugation for $15 \mathrm{~min}$ at $6,000 \mathrm{~g}$, re-suspended in infiltration media $(10 \mathrm{mM} \mathrm{MgCl} 2$ and $10 \mathrm{mM}$ MES containing $150 \mathrm{mM}$ acetosyringone) for $2 \mathrm{~h}$ at room temperature to induce T-DNA transfer functions [36], and then adjusted to an OD600 of 0.8. After the infiltration of the Agrobacterium suspension into the abaxial surfaces of tobacco leaves from a syringe without a needle [37], the tobacco plants were maintained in a moist chamber at $26^{\circ} \mathrm{C}$ for $48 \mathrm{~h}$ for GUS activity analysis.

GUS activity in these tobacco leaves was measured as described by Jefferson [38]. Tobacco leaf tissues were homogenized in $1 \mathrm{ml}$ of extraction buffer $(50 \mathrm{mM}$ $\mathrm{NaH}_{2} \mathrm{PO}_{4}, \mathrm{pH}$ 7.0, 10 mM EDTA, 0.1\% Triton X-100, 0.1\% $(w / v)$ sodium laurylsarcosine, $10 \mathrm{mM} \beta$-mercaptoethanol, and $6 \mathrm{mM} \mathrm{L}$-ascorbic acid). After centrifugation for 10 $\min$ at $12,000 \mathrm{rpm}\left(4^{\circ} \mathrm{C}\right)$, the supernatant was transferred to a fresh microtube. The spectrophotometric reaction was carried out in a $1 \mathrm{~mL}$ volume with $1 \mathrm{mM}$ PNPG (P-nitrophenyl- $\beta$-D-glucuronide) in the extraction buffer supplemented with protein extract supernatants. GUS activity was normalized to the protein concentration in each of the crude extracts and was expressed as nmol of P-nitrophenol min/mg protein. The total protein in the sample extract was quantified using bovine serum albumin as a standard, according to the Bradford method [39]. The GUS measurement was repeated at least three times.

\section{RT-PCR analysis using the WAVE dHPLC system}

Total RNA was isolated using Trizol (Invitrogen, Carlsbad, CA, USA) according to the manufacturer's instructions. We used gene-specific primers (5'-CA GCTCCACACCTGTACGT-3' and 5'-CCATGCTCA GCGACTTGATG-3' for ZmNAC1, and 5'-ACGTG CATTACCATCCAATGC-3', 5'-CTGCATGACGAGG TATGTACG-3' for ZmmiR164b) to obtain the corresponding $\mathrm{CDNA}$ from each inbred line by RT-PCR. The PCR products were then sequenced to identify allelespecific sequence polymorphisms between the inbred lines
87-1 and Zong3 that would allow separation of the two parental alleles on the WAVE dHPLC system (Transgenomic, Omaha, NE). The gene-specific primers were designed to amplify the regions that are conserved between alleles and that encompass a sequence polymorphism indel to minimize the amplification preference of either allele and to optimize the amplicon for WAVE analysis. The $\beta$-actin gene fragment was amplified as a positive control using 26 cycles. Three PCR replicates were performed for each RNA sample. The RTPCR products were then separated and quantified by the WAVE dHPLC system, and detailed WAVE dHPLC analysis was performed according to the manufacturer's instructions [40].

\section{Additional files}

\begin{abstract}
Additional file 1: Polygenetic tree of 175 maize NAC and 105 Arabidopsis NAC proteins. The unrooted phylogenetic tree of NAC proteins was constructed using the CLUSTAL X program with the neighbor-joining method. In this figure, 105 Arabidopsis NAC proteins and 175 maize NAC proteins are classified into three large groups, separated by blue lines. Red arcs represent 14 subgroups and pink dots denote putative miR164 target genes in maize. The sequences of 105 Arabidopsis NAC proteins are from reference [3].
\end{abstract}

Additional file 2: Putative ZmNACs were obtained as the putative miR164 target genes. This figure shows the reverse complementary site for mature miR164 and 7 ZmNACs.

Additional file 3: The full-length cDNA of ZmNAC1. This figure shows the full length cDNA of $Z m N A C 1$, in which the highly conserved region of the NAC domain is boxed; the red box indicates the (NLS) nuclear localization signal as noted between amino acids 121 and 138 .

Additional file 4: The figure shows the variation of lateral root density among RILs. 40 RILs were investigated 8days after germination, 4 plants per genotype were investigated for lateral root density. Lateral root numbers in primary root were counted manually and was divided by the total length of the primary root as a parameter for lateral root density (De Smet et al. 2012). Analysis of variance for the lateral root density among 40 RILs were performed.

Additional file 5: The expression levels of ZmNAC1 among RILs. This figure shows the expression of ZmNAC1 in the RILs, which was investigated 8 days after germination by planting eight plants for each genotype, half of which were collected for gene expression analysis.

Additional file 6: The secondary structure of ZmmiR164b in 87-1 and Zong3. This figure shows the secondary structure of ZmmiR164b in 87-1 and Zong3 as determined by mFold software. The good hairpin structure indicates that both of them can give rise to mature miR164.

Additional file 7: The correlation between lateral root numbers and expression of mir164b in 40 RILs. This figure shows that a large variation exists in both lateral root numbers and the expression of miR164b among 40 RILs. The correlation coefficient value was calculated, and no significant correlation was found.

Additional file 8: Comparison of the ZmNAC1 promoter between 87-1 and Zong3. This figure shows that no large variation exists in the $1 \mathrm{kB}$ region of the $Z m N A C 1$ promoter between two inbred lines, with the exception of one SNP.

Authors' contributions

Jing Li and Guanghui Guo carried out the main experiments and drafted the manuscript, and they contributed equally to this study. Weiwei Guo, Ganggang Guo, and Dan Tong greatly helped the first author in the transgenic work, RIL analysis and Northern blot analysis. Zhongfu Ni 
contributed by analyzing the data. Yingyin Yao and Qixin Sun designed the research and finished the manuscript. All authors read and approved the final manuscript.

\section{Acknowledgments}

This work was financially supported by the National Basic Research Program of China (2012CB910900), 863 Project of China (2012AA10A309) and the National Natural Science Foundation of China (30930058, 30600392, 30871529).

\section{Author details}

${ }^{1}$ State Key Laboratory for Agrobiotechnology and Key Laboratory of Crop Heterosis and Utilization (MOE) and Key Laboratory of Crop Genomics and Genetic Improvement (MOA), Beijing Key Laboratory of Crop Genetic Improvement, China Agricultural University, Beijing 100193, China. ${ }^{2}$ National Plant Gene Research Centre (Beijing), Beijing 100193, China. ${ }^{3}$ Department of Plant Genetics \& Breeding, China Agricultural University, Yuanmingyuan Xi Road No. 2, Haidian District, Beijing 100193, China.

Received: 15 August 2012 Accepted: 20 November 2012

Published: 21 November 2012

\section{References}

1. Souer E, van Houwelingen A, Kloos D, Mol J, Koes R: The No Apical Meristem gene of Petunia is required for pattern formation in embryos and flowers and is expressed at meristem and primordia boundaries. Cell 1996, 85:159-170.

2. Aida M, Ishida T, Fukaki H, Fujisawa H, Tasaka M: Genes involved in organ separation in Arabidopsis: an analysis of the cup-shaped cotyledon mutant. Plant Cell 1997, 9:841-857.

3. Ooka H, Satoh K, Doi K, Nagata T, Otomo Y, Murakami K, Matsubara K, Osato N, Kawai J, Carninci P, Hayashizaki Y, Suzuki K, Kojima K, Takahara Y, Yamamoto K, Kikuchi S: Comprehensive analysis of NAC family genes in Oryza sativa and Arabidopsis thaliana. DNA Res 2003, 10:239-247.

4. Riechmann JL, Heard J, Martin G, Reuber L, Jiang CZ, Keddie J, Adam L, Pineda O, Ratcliffe OJ, Samaha RR, Creelman R, Pilgrim M, Broun P, Zhang JZ, Ghandehari D, Sherman BK, YU GL: Arabidopsis transcription factors: genome-wide comparative analysis among eukaryotes. Science 2000, 290:2105-2110.

5. Fang Y, You J, Xie K, Xie W, Xiong L: Systematic sequence analysis and identification of tissue-specific or stress-responsive genes of NAC transcription factor family in rice. Mol Genet Genomics 2008, 280:535-546.

6. Vroemen CW, Mordhorst AP, Albrecht C, Kwaaitaal MACJ, de Vries SC: The CUP-SHAPED COTYLEDON3 gene is required for boundary and shoot meristem formation in Arabidopsis. Plant Cell 2003, 15:1563-1577.

7. Sablowski RW, Meyerowitz EM: A homolog of NO APICAL MERISTEM is an immediate target of the floral homeotic genes APETALA3/PISTILLATA. Cell 1998, 92:93-103.

8. Xie $\mathrm{Q}$, Frugis $\mathrm{G}$, Colgan $\mathrm{D}$, Chua $\mathrm{NH}$ : Arabidopsis NAC1 transduces auxin signal downstream of TIR1 to promote lateral root development. Genes Dev 2000, 14:3024-3036.

9. Collinge M, Boller T: Differential induction of two potato genes, Stprx2 and StNAC, in response to infection by Phytophthora infestans and to wounding. Plant Mol Biol 2001, 46:521-529.

10. Hegedus D, Yu M, Baldwin D, Gruber M, Sharpe A, Parkin I, Whitwill S, Lydiate D: Molecular characterization of Brassica napus NAC domain transcriptional activators induced in response to biotic and abiotic stress. Plant Mol Biol 2003, 53:383-397.

11. Tran LS, Nakashima K, Sakuma Y, Simpson SD, Fujita Y, Maruyama K, Fujita $M$, Seki M, Shinozaki K, Yamaguchi-Shinozaki K: Isolation and functional analysis of Arabidopsis stress inducible NAC transcription factors that bind to a drought responsive cis-element in the early responsive to dehydration stress 1 promoter. Plant Cell 2004, 16:2481-2498.

12. Hu H, Dai M, Yao J, Xiao B, Li X, Zhang Q, Xiong L: Overexpressing a NAM, ATAF, and CUC (NAC) transcription factor enhances drought resistance and salt tolerance in rice. Proc Natl Acad Sci 2006, 103:12987-12992.

13. Hu H, You J, Fang Y, Zhu X, Qi Z, Xiong L: Characterization of transcription factor gene SNAC2 conferring cold and salt tolerance in rice. Plant $\mathrm{Mol}$ Biol 2008, 67:169-181.

14. Bartel DP: MicroRNAs: genomics, biogenesis, mechanism, and function. Cell 2004, 116:281-297.
15. Llave C, Xie ZX, Kasschau KD, Carrington JC: Cleavage of SCARECROW-like mRNA targets directed by a class of Arabidopsis miRNA. Science 2002, 297:2053-2056.

16. Schwab R, Palatnik JF, Riester M, Schommer C, Schmid M, Weigel D: Specific effects of microRNAs on the plant transcriptome. Dev Cell 2005, 8:517-527.

17. Mallory AC, Dugas DV, Bartel DP, Bartel B: MicroRNA regulation of NAC-domain targets is required for proper formation and separation of adjacent embryonic, vegetative, and floral organs. Curr Biol 2004, 14:1035-1046.

18. Guo HS, Xie Q, Fei JF: MicroRNA directs mRNA cleavage of the transcription factor NAC1 to down regulate auxin signals for Arabidopsis lateral root development. Plant Cell 2005, 17:1376-1386.

19. Laufs $P$, Peaucelle $A$, Morin $H$, Traas J: MicroRNA regulation of the CUC genes is required for boundary size control in Arabidopsis meristems. Development 2004, 131:4311-4322.

20. Baker CC, Sieber $P$, Wellmer F, Meyerowitz EM: The early extra petals1 mutant uncovers a role for microRNA miR164c in regulating petal number in Arabidopsis. Curr Biol 2005, 15:303-315.

21. Dubrovsky JG, Rost TL: Pericycle. In Encyclopaedia of life sciences. Edited by Roberts KR. Chichester, UK: John Wiley and Sons Ltd; 2005. doi:10.1038/npg.els.0002085.

22. Parizot B, Laplaze L, Ricaud L, Boucheron-Dubuisson E, Bayle V, Bonke M, De Smet I, Poethig SR, Helariutta Y, Haseloff J, Chriqui D, Beeckman T, Nussaume L: Diarch symmetry of the vascular bundle in Arabidopsis root encompasses the pericycle and is reflected in distich lateral root initiation. Plant Physiol 2008, 146:140-148

23. De Smet I, Vanneste $S$, Inze D, Beeckman T: Lateral root initiation or the birth of a new meristem. Plant Mol Biol 2006, 60:871-887.

24. Hochholdinger F, Zimmermann R: Conserved and diverse mechanisms in root development. Curr Opin Plant Biol 2008, 11:70-74.

25. Fukaki H, Nakao Y, Okushima Y, Theologis A, Tasaka M: Tissue-specific expression of stabilized SOLITARY-ROOT/IAA14 alters lateral root development in Arabidopsis. Plant J 2005, 44:382-395.

26. Okushima Y, Fukaki H, Onoda M, Theologis A, Tasaka M: ARF7 and ARF19 regulate lateral root formation via direct activation of $L B D / A S L$ genes in Arabidopsis. Plant Cell 2007, 19:118-130.

27. Xie Q, Guo HS, Dallman G, Fang S, Weissman AM, Chua NH: SINAT5 promotes ubiquitin-related degradation of NAC1 to attenuate auxin signals. Nature 2002, 419:167-170.

28. Yan H, Yuan W, Velculescu VE, Vogelstein B, Kinzler KW: Allelic variation in human gene expression. Science 2002, 297:1143.

29. Wittkopp PJ, Haerum BK, Clark AG: Evolutionary changes in cis and trans gene regulation. Nature 2004, 430:85-88.

30. Palatnik JF, Allen E, Wu XL, Schommer C, Schwab R, Carrington JC, Weigel D: Control of leaf morphogenesis by microRNAs. Nature 2003, 425:257-263.

31. Kidner CA, Martienssen RA: Spatially restricted microRNA directs leaf polarity through ARGONAUTE1. Nature 2004, 428:81-84.

32. Mallory AC, Reinhart BJ, Jones-Rhoades M, Tang G, Zamore PD, Barton MK, Bartel DP: MicroRNA control of PHABULOSA in leaf development: importance of pairing to the mi- microRNA 5'region. EMBO J 2004, 23:3356-3364.

33. Chen $\mathrm{X}$ : A microRNA as a translational repressor of APETALA2 in Arabidopsis flower development. Science 2004, 303:2022-2025.

34. De Smet I, Philip JW, Bengough AG, Lionel D, Parizot B, Casimiro I, Heidstra R, Laskowski M, Lepetit M, Hochholdinger F, Draye X, Zhang H, Broadley MR, Benjamin P', Hammond JP, Fukaki H, Mooney S, Lynch JP, Nacry P, Schurr U, Laplaze L, Benfey P, Beeckman T, Bennetta M: Analyzing lateral root development: How to move forward. Plant Cell 2012, 24:15-20.

35. Clough SJ, Bent AF: Floral dip: a simplified method for agrobacteriummediated transformation of Arabidopsis thaliana. Plant J 1998, 16:735-743.

36. Hellens RP, Edwards EA, Leyland NR, Bean S, Mullineaux PM: pGreen: a versatile and flexible binary $\mathrm{Ti}$ vector for Agrobacterium mediated plant transformation. Plant Mol Biol 2000, 42:819-832.

37. Kim BS, Kim YC, Shin KS, Kim JH: Near-isogenic lines for genes conferring hypersensitive resistance to bacterial spot in chili pepper. Plant Pathol $J$ 2007, 23:155-160.

38. Jefferson RA, Kavanagh TA, Bevan MW: GUS fusions: hglucouronidase as a sensitive and versatile gene fusion marker in higher plants. EMBO J 1987, 13:3901-3907. 
39. Bradford MM: A rapid sensitive method for the quantitation of microgram quantities of protein utilizing the principle of protein-dye binding. Anal Biochem 1976, 72:248-254.

40. Guo M, Rupe MA, Danilevskaya ON, Yang X, Hu Z: Genome-wide mRNA profiling reveals heterochronic allelic variation and a new imprinted gene in hybrid maize endosperm. Plant J 2003, 36:30-44.

doi:10.1186/1471-2229-12-220

Cite this article as: Li et al:: miRNA164-directed cleavage of ZmNAC1 confers lateral root development in maize (Zea mays L.). BMC Plant Biology 2012 12:220.

\section{Submit your next manuscript to BioMed Central and take full advantage of:}

- Convenient online submission

- Thorough peer review

- No space constraints or color figure charges

- Immediate publication on acceptance

- Inclusion in PubMed, CAS, Scopus and Google Scholar

- Research which is freely available for redistribution 